\title{
ANALISIS FAKTOR KETERLAMBATAN PROYEK KONSTRUKSI PALING DOMINAN DI KABUPATEN ACEH UTARA
}

\author{
Muhammad Derry Safrizal ${ }^{1)}$, Anita Rauzana ${ }^{2)}$, Muttaqin ${ }^{3)}$ \\ Jurusan Teknik Sipil, Universitas Syiah Kuala, Darussalam Jl. Tgk. Hasan Krueng Kalee, \\ Kopelma Darussalam, Syiah Kuala, Kota Banda Aceh, Aceh 23111 \\ Email:m.derrysafrizal@gmail.com ${ }^{1)}$, anrauzana@gmail.com ${ }^{2)}$,muttaqin@uusyiah.ac.id ${ }^{3)}$
}

DOI: http://dx.doi.org/10.29103/tj.v9i2.210

(Received: May 2019 / Revised: August 2019 / Accepted: August 2019)

\begin{abstract}
Abstrak
Kinerja suatu proyek tidak akan berjalan dengan baik jika pengawasan dan pengendalian tidak dijalankan, maka akan mengakibatkan terjadinya keterlambatan dalam proses penyelesaian suatu proyek. Keterlambatan pekerjaan proyek memiliki berbagai macam penyebab baik yang diakibatkan oleh kelalaian yang dilakukan oleh manusia hingga keterlambatan yang terjadi akibat faktor alam. Keterlambatan pelaksanaan akan mengakibatkan berbagai permasalahan baru dalam proses pekerjaan proyek, termaksud dari segi meningkatnya biaya pelaksanaan proyek. Tujuan pada penelitian ini adalah menganalisis mengenai faktor-faktor penyebab keterlambatan pelaksanaan proyek konstruksi serta mengetahui pengaruhnya terhadap biaya diwilayah Aceh Utara. Metode penelitian ini menggunakan pendekatan kuantitatif dan kualitatif melalui teknik observasi dengan cara menyebarkan kuesioner kepada para pihak kontraktor kontruksi yang terdaftar pada Lembaga Pengembangan Jasa Konstruksi (LPJK). Berdasarkan data LPJK pada tahun 2018 jumlah kontraktor yang berdomisili diKabupaten Aceh Utara sebanyak 83 kontraktor yang berkualifikasi $\mathrm{K}_{3}$, $\mathrm{M}_{1}, \mathrm{M}_{2}, \mathrm{~B}_{1}$, dan $\mathrm{B}_{2}$. Maka dikarenakan populasi kurang dari 100, oleh kerna itu adapun sampel/responden yang diambil dalam penelitian ini semua populasi, yaitu sebanyak 83 perusahaan kontraktor yang berdomisili diKabupaten Aceh Utara. Variabel didalam penelitian ini terdiri dari 2 variabel yaitu variabel bebas/variabel X adalah Faktor-Faktor Penyebab Keterlambatan Proyek, dan variabel terikat/variabel Y adalah Biaya Proyek. Hasil dari penelitian ini berdasarkan persepsi responden faktor yang paling dominan penyebab terjadinya keterlambatan proyek konstruksi diKabupaten Aceh Utara adalah disebabkan oleh faktor pelaksanaan dan hubungan kerja.

Kata Kunci : Keterlambatan, proyek konstruksi, pengaruh biaya
\end{abstract}

\begin{abstract}
The performance of a project will not work well if supervision and control are not carried out, then delays will be made in the process of completing a project. Delay in project work has a variety of good causes caused by negligence carried out by humans to delay that occur due to natural factors. Delay in implementation will discuss new problems in the project work process, terms that are intended as part of the agreement on the cost of implementing the project. The purpose of this study was to analyze the factors that caused the delay in the implementation of the project and to study the effects on costs realized in North Aceh. This research method used quantitative and
\end{abstract}


qualitative methods through observation methods by asking questions to the parties that contribute to the Construction Services Development Institute (LPJK). Based on data from LPJK in 2018 the number of contractors domiciled in North Aceh Regency were 83 contractors who qualified K3, M1, M2, B1 and B2. Thus the population is less than 100 , by Kerna, while the sample / respondent taken in this study were all populations, namely 83 contracting companies domiciled in North Aceh Regency. The variables in this study consist of 2 variables, namely the independent variable / variable X was the causes of Project Delay, and the required variable / Y variable was the Project Cost. The results of this study based on respondents' perceptions of the most dominant factors causing delays in construction projects in North Aceh Regency were caused by implementation factors and work relations.

Keywords: Delay, construction project, cost effect.

\section{Latar Belakang}

Setiap proyek konstruksi mempunyai rencana pelaksanaan yang tertentu, kapan pelaksanaan proyek tersebut harus di mulai, kapan harus diselesaikan dan bagaimana proyek tersebut dikerjakan, serta bagaimana penyediaan sumber dayanya, pembuatan rencana pelaksanaan itu dibuat, kerena itu permasalahan akan timbul apabila tidak ada kesesuaian antara rencana yang telah dibuat dengan kenyataan yang sebenarnya. Masalah yang timbul akan menjadi suatu hambatan sehingga terjadinya keterlambatan dalam penyelesaian pelaksanaan proyek konstruksi. keterlambatan pekerjaan memiliki berbagai macam-macam penyebab baik yang diakibatkan oleh kelalaian yang dilakukan oleh manusia hingga keterlambatan yang terjadi akibat faktor alam. Keterlambatan pelaksanaan akan mengakibatkan berbagai permasalahan baru dalam proses pekerjaan proyek, termaksud dari segi meningkatnya biaya pelaksanaan proyek.

Dampak dari keterlambatan pelaksanaan proyek berpotensi besar terhadap meningkatnya biaya pelaksanaan proyek, selain itu keterlambatan juga berpengaruh pada adanya time overrun, perselisihan, dan pemutusan hubungan kerja. Hal ini dapat menyebabkan kerugian bagi pihak-pihak yang terkait, Oleh karena itu diperlukan perhatian lebih terhadap keterlambatan pelaksanaan proyek.

Maka kerena itu pada penelitian ini akan mengganalisis mengenai faktor penyebab keterlambatan pelaksanaan proyek konstruksi serta mengetahui pengaruhnya terhadap biaya proyek di wilayah Aceh Utara.

\section{Metode Penelitian}

Objek penelitian merupakan hal yang menjadi sasaran yang hendak dicapai untuk mendapatkan jawaban dari permasalahan yang terjadi. Objek dari penelitian ini yaitu menganalisis pengaruh faktor-faktor penyebab keterlambatan proyek konstruksi terhadap biaya di wilayah Aceh Utara.

\subsection{Sumber Data}

Sumber data merupakan subyek dari mana data dapat diperoleh. Dalam penelitian ini sumber data yang digunakan dua sumber data yaitu:

\section{Data Primer}

Adapun yang menjadi sumber data primer berupa jawaban responden dari pertanyaan-pertanyaan yang telah dirancang pada kuesioner. 
2. Data sekunder

Data sekunder berupa jumlah seluruh kualifikasi perusahaan yang bersumber dari LPJK.

\subsection{Penentuan Sampel}

Dalam penelitian ini populasi yang diambil yaitu kontraktor atau orangorang yang sudah berpengalaman di bidang proyek konstruksi, seperti tenaga ahli, project manager, site engineer, pelaksana lapangan dan supervisor. Maka dikarenakan populasi kurang dari 100, oleh kerna itu adapun untuk sampel yang di ambil dalam penelitian ini semua populasi (Arikunto 2010), yaitu sebanyak 83 perusahaan kontraktor yang berdomisili di Kabupaten Aceh Utara

\subsection{Uji Validitas}

Uji validitas adalah uji yang digunakan untuk menunjukkan sejauh mana alat ukur yang digunakan dalam suatu mengukur apa yang diukur. Maksudnya untuk mengukur valid atau tidaknya suatu kuesioner dilihat jika pertanyaan dalam kuesioner tersebut mampu mengungkapkan suatu yang akan diukur oleh suatu kuesioner tersebut. Kriteria pengujian apabila $r_{\text {hitung }}>r_{\text {tabel }}$ dengan $\alpha$ sebesar 0,05 maka alat ukur tersebut dinyatakan valid, dan sebaliknya apabila $r_{\text {hitung }}<r_{\text {tabel }}$ maka alat ukur tersebut adalah tidak valid (Priyanto 2010).

Adapun pertanyaan-pertanyaannya diantara adalah pertanyaan tentang factor disain yaitu: Spesifikasi teknis tidak jelas dan kurang tegas kerena terlalu umum (A1), Desain tidak jelas, tidak sinkron antara satu item dengan item lainnya (A2), Shop drawing tidak siap pada saatnya, tidak ada kesempatan untuk mempelajari (A3), Data dan informasi proyek yang kurang lengkap (A4), Perubahan desain (A5), Penentuan durasi waktu kerja yang tidak seksama/tepat (A6), Rencana urutan kerja yang tidak tersusun dengan baik (A7).

Pertanyaan lain adalah tentang factor pelaksanaan dan hubungankerja yaitu: Kordinasi proyek yang cukup rumit (B1), Pelaksanaan proyek berimprovisasi kerena kurang perencanaan (B2), Proses pekerjaan yang rumit dan khusus, padahal bisa disederhanakan (B3), Fungsi pengawasan lemah bahkan tanpa pengawasan (B4), Adanya banyak pekerjaan tambahan (B5), Perubahan jadwal pelaksanaan (B6), Kegagalan pemilik mengkoordinasi pekerjaan dari banyak kontraktor/sub kontraktor (B7), Daftar pekerjaan tidak lengkap (B8), hanya diberikan secara sedikit demi sedikit (B9), Penundaan pekerjaan kerena alasan keuangan dan hokum (B10), Kesulitan pendanaan pekerjaan kerena alasan keuangan dan hokum (B11), Proses persetujuan ijin kerja yang bertele-tele (B12).

Penyimpangan waktu pengiriman antara pengadaan material dengan peralatan pertanyaannya adalah: Bahan dan material yang terkirim tidak sesuai dengan spesifikasi (C1), Kedatangan bahan terlambat dari jadwal kerena tidak ready stock (C2), Ukuran bahan produk tidak tepat dan tidak baku (C3), Harga bahan yang berfluktuasi setiap harinya (C4), Banyak meterial-material yang hilang di lokasi proyek (C5), Kerkurangan bahan waktu pelaksanaan (C6), Standar material dalam spesifikasi tidak ada di pasaran (C7), Kontrol kualitas bahan yang buruk (C8), Jarak tempuh sumber material yang jauh (C9), Perubahan/penambahan spesifikasi meterial dipergunakan (C10).

Pertanyaan tentang tenaga kerja yaitu: Kualitas tenaga kerja yang 
buruk/kurang memadai (D1), Kekurangan tenaga kerja (D2), Kurangnya pengalaman tenaga kerja (D3), Bekerja tidak sesuai prosedur (D4), Tidak menguasai pekerjaan di lapangan (D5), Kurang kompaknya tim pelaksanaan kegiatan (D6), Kedisiplinan tenaga kerja yang kurang (D7), Penggantian tenaga kerja baru (D8).

Pertanyaan tentang factor peralatan yaitu: Pengadaan peralatan yang tidak tepat waktu (E1), Peralatan yang tiba-tiba rusak pada saat proyek berjalan (E2), Peralatan tidak memadai (E3), Kekurangan peralatan waktu pelaksanaan (E4), Peralatan sering rusak (E5), Kapasitas alat kurang (E6).

Pertanyaan factor kondisi lapangan terdiri dari: Kondisi lapangan yang berbeda dengan kontrak (F1), Hujan yang turun berhari-hari tanpa henti (F2), Cuaca yang tidak lazim/tidak sesuai dengan musimnya (F3), Transportasi ke lokasi proyek yang sulit (F4), Adanya konflik kepentingan (F5), Adanya pertentangan lama yang belum terselesaikan (F6).

Pertanyaan tentang factor di luar kemampuan kontraktor terdiri dari: Terjadinya hal yang tak terduga seperti kebakaran , banjir, gempa bumi, badai (G1), Terjadinya kecelakaan kerja (G2), Adanya pemogokan buruh (G3), Adanya huru-hara/kerusuhan, perang (G4), Perubahan situasi atau kebijakan politik/ekonomi pemerintahan (G5), dan Masalah pembebasan lahan (G6).

\subsection{Uji Reliabilitas}

Uji reliabilitas menunjukkan sejauh mana instrument dapat memberikan hasil pengukuran yang konsisten apabila pengukuran dilakukan berulang-ulang. Pengukuran reliabilitas tersebut dilakukan dengan menggunakan rumus alpha ronbach (Triton 2005), dengan menggunakan rumus persamaan (2.3). Kriteria uji reliabilitas dengan rumus alpha adalah apabila rhitung > rtabel $(0,6)$ maka alat ukur tersebut reliabel dan juga sebaliknya, jika rhitung < rtabel $(0,6)$ maka alat ukur tidak reliabel (Arikunto 2006).

\subsection{Analisa Data}

Metode analisis deskriptif digunakan dengan cara mengumpulkan, mengolah, menyajikan data sehingga muda dipahami, dan menginterpretasi data sehingga diperoleh gambaran yang jelas mengenai fakta-fakta, masalah dan penyajiannya dalam bentuk tabel distribusi frekuensi (Narbuko dan Achmadi, 2004). Statistik deskriptif ini dilakukan untuk mengetahui permasalahan faktorfaktor penyebab keterlambatan pelaksanaan proyek konstruksi di Aceh Utara.

\section{Hasil dan Pembahasan}

\subsection{Uji Validitas}

Pengujian validitas data dalam penelitian ini dilakukan secara statistik, yaitu dengan menggunakan uji pearson correlation. Pertanyaan dinyatakan valid jika nilai r-hitung $>$ r-tabel atau nilai p-value lebih kecil dari alpha 5\%. Hasil mengenai uji validitas dapat dilihat pada Tabel 1 . 
Tabel 1 Hasil uji validitas

\begin{tabular}{|c|c|c|c|c|}
\hline Variabel & $\begin{array}{c}\text { Item } \\
\text { Pertanyaan }\end{array}$ & r-hitung & r-tabel & Keterangan \\
\hline \multirow{7}{*}{$\begin{array}{l}\text { Faktor Desain dan } \\
\text { Perencanaan (X1) }\end{array}$} & A1 & 0,906 & \multirow{7}{*}{0,196} & Valid \\
\hline & $\mathrm{A} 2$ & 0,690 & & Valid \\
\hline & A3 & 0,819 & & Valid \\
\hline & A4 & 0,954 & & Valid \\
\hline & A5 & 0,927 & & Valid \\
\hline & A6 & 0,883 & & Valid \\
\hline & A7 & 0,894 & & Valid \\
\hline \multirow{12}{*}{$\begin{array}{c}\text { Faktor } \\
\text { Pelaksanaan dan } \\
\text { Hubungan Kerja } \\
\text { (X2) }\end{array}$} & $\mathrm{B} 1$ & 0,852 & \multirow{12}{*}{0,196} & Valid \\
\hline & $\mathrm{B} 2$ & 0,832 & & Valid \\
\hline & B3 & 0,695 & & Valid \\
\hline & B4 & 0,885 & & Valid \\
\hline & B5 & 0,863 & & Valid \\
\hline & B6 & 0,878 & & Valid \\
\hline & B7 & 0,857 & & Valid \\
\hline & B8 & 0,636 & & Valid \\
\hline & B9 & 0,857 & & Valid \\
\hline & B10 & 0,814 & & Valid \\
\hline & B11 & 0,850 & & Valid \\
\hline & B12 & 0,806 & & Valid \\
\hline \multirow{10}{*}{$\begin{array}{l}\text { Faktor Material } \\
\text { (X3) }\end{array}$} & $\mathrm{C} 1$ & 0,878 & \multirow{10}{*}{0,196} & Valid \\
\hline & $\mathrm{C} 2$ & 0,865 & & Valid \\
\hline & $\mathrm{C} 3$ & 0,677 & & Valid \\
\hline & $\mathrm{C} 4$ & 0,892 & & Valid \\
\hline & $\mathrm{C} 5$ & 0,697 & & Valid \\
\hline & C6 & 0,622 & & Valid \\
\hline & $\mathrm{C} 7$ & 0,539 & & Valid \\
\hline & $\mathrm{C} 8$ & 0,908 & & Valid \\
\hline & $\mathrm{C} 9$ & 0,893 & & Valid \\
\hline & $\mathrm{C} 10$ & 0,536 & & Valid \\
\hline \multirow{8}{*}{$\begin{array}{l}\text { Faktor Tenaga } \\
\text { Kerja (X4) }\end{array}$} & D1 & 0,809 & \multirow{8}{*}{0,196} & Valid \\
\hline & D2 & 0,882 & & Valid \\
\hline & D3 & 0,910 & & Valid \\
\hline & D4 & 0,939 & & Valid \\
\hline & D5 & 0,864 & & Valid \\
\hline & D6 & 0,798 & & Valid \\
\hline & D7 & 0,812 & & Valid \\
\hline & D8 & 0,645 & & Valid \\
\hline \multirow{6}{*}{$\begin{array}{l}\text { Faktor Peralatan } \\
\text { (X5) }\end{array}$} & E1 & 0,812 & \multirow{6}{*}{0,196} & Valid \\
\hline & E2 & 0,844 & & Valid \\
\hline & E3 & 0,780 & & Valid \\
\hline & E4 & 0,876 & & Valid \\
\hline & E5 & 0,764 & & Valid \\
\hline & E6 & 0,478 & & Valid \\
\hline
\end{tabular}

Analisis Faktor Keterlambatan Proyek Konstruksi Paling Dominan di Kabupaten Aceh Utara - Muhammad Derry Safrizal, Anita Rauzana, Muttaqin 


\begin{tabular}{|c|c|c|c|c|}
\hline \multirow{6}{*}{$\begin{array}{l}\text { Faktor Kondisi } \\
\text { Lapangan (X6) }\end{array}$} & $\mathrm{F} 1$ & 0,754 & \multirow{6}{*}{0,196} & Valid \\
\hline & $\mathrm{F} 2$ & 0,860 & & Valid \\
\hline & F3 & 0,826 & & Valid \\
\hline & $\mathrm{F} 4$ & 0,791 & & Valid \\
\hline & F5 & 0,755 & & Valid \\
\hline & F6 & 0,457 & & Valid \\
\hline \multirow{6}{*}{$\begin{array}{l}\text { Faktor di Luar } \\
\text { Kemampuan } \\
\text { Kontraktor (X7) }\end{array}$} & G1 & 0,792 & \multirow{6}{*}{0,196} & Valid \\
\hline & G2 & 0,696 & & Valid \\
\hline & G3 & 0,881 & & Valid \\
\hline & G4 & 0,834 & & Valid \\
\hline & G5 & 0,728 & & Valid \\
\hline & D6 & 0,855 & & Valid \\
\hline
\end{tabular}

Berdasarkan Tabel 1 dapat dinyatakan bahwa seluruh pernyataan dari masing-masing variabel dinyatakan valid karena memiliki hubungan yang positif terhadap total skor konstruk. Hubungan positif ini terjadi karena masing-masing pernyataan memiliki nilai signifikansi dibawah alpha 5\% dan nilai r-hitung lebih besar dari nilai $r$ - tabel.

\subsection{Uji Reliabilitas}

Uji reliabilitas merupakan alat ukur untuk mengukur suatu kuesioner yang merupakan indikator dari variabel. Suatu kuesioner dikatakan reliabel atau handal jika jawaban seseorang terhadap pernyataan adalah konsisten dari waktu ke waktu. Untuk mengetahui reliabel atau tidak suatu variabel dilakukan uji statistik dengan melihat nilai cronbach alpha. Kriteria yang digunakan adalah:

- Jika nilai cronbach alpha> 0,60 maka pernyataan yang digunakan untuk mengukur variabel tersebut adalah reliabel.

- Jika nilai cronbach alpha< 0,60 maka pernyataan yang digunakan untuk mengukur variabel tersebut adalah tidak reliabel.

Hasil uji reliabilitas dalam penelitian ini menghasilkan nilai cronbach alpha dari masing-masing variabel $>0.60$, sehingga seluruh variabel yang digunakan dinyatakan reliabel. Nilai cronbach alpha untuk masing-masing variabel dapat dilihat pada tabel berikut.

Tabel 2 Hasil uji reliabilitas

\begin{tabular}{ccccc}
\hline Variabel & $\begin{array}{c}\text { Jumlah } \\
\text { Item }\end{array}$ & $\begin{array}{c}\text { Cronbach } \\
\text { Alpha }\end{array}$ & $\begin{array}{c}\text { Nilai Kritis } \\
\text { Cronbach } \\
\text { Alpha }\end{array}$ & Keterangan \\
\hline $\begin{array}{c}\text { Faktor Desain dan } \\
\text { Perencanaan (X1) }\end{array}$ & 7 & 0,938 & 0,600 & Reliabel \\
\hline $\begin{array}{c}\text { Faktor Pelaksanaan dan } \\
\text { Hubungan Kerja (X2) }\end{array}$ & 12 & 0,954 & 0,600 & Reliabel \\
\hline Faktor Material (X3) & 10 & 0,914 & 0,600 & Reliabel \\
\hline Faktor Tenaga Kerja (X4) & 8 & 0,931 & 0,600 & Reliabel \\
\hline Faktor Peralatan (X5) & 6 & 0,838 & 0,600 & Reliabel \\
\hline $\begin{array}{l}\text { Analisis Faktor Keterlambatan Proyek Konstruksi Paling Dominan di Kabupaten Aceh } \\
\text { Utara - Muhammad Derry Safrizal, Anita Rauzana, Muttaqin }\end{array}$ & 150 \\
\end{tabular}




\begin{tabular}{ccccc}
\hline $\begin{array}{c}\text { Faktor Kondisi Lapangan } \\
(\mathrm{X6})\end{array}$ & 6 & 0,838 & 0,600 & Reliabel \\
\hline $\begin{array}{c}\text { Faktor di Luar Kemampuan } \\
\text { Kontraktor (X7) }\end{array}$ & 6 & 0,877 & 0,600 & Reliabel \\
\hline
\end{tabular}

Tabel 2 menunjukkan bahwa seluruh variabel penelitian reliabel karena memiliki nilai cronbach alpha di atas batas kritis 0,6 .

\subsection{Analisis Deskriptif}

Berdasarkan perhitungan nilai mean dari semua indikator dan faktor yang telah diuraikan pada halaman-halaman sebelumnya, maka berikut ini dapaat diperlihatkan rekapitulasi mean dari masing-masing faktor beserta peringkatnya, terangkum dalam Tabel 3.

Tabel 3 Rekapitulasi Hasil Analisis Deskriptif

\begin{tabular}{clcc}
\hline No. & \multicolumn{1}{c}{ Variabel } & Mean & Peringkat \\
\hline X1 & Faktor Desain dan Perencanaan & 4,30 & 2 \\
\hline X2 & Faktor Pelaksanaan dan Hubungan Kerja & 4,31 & 1 \\
\hline X3 & Faktor Material & 4,22 & 7 \\
\hline X4 & Faktor Tenaga Kerja & 4,27 & 4 \\
\hline X5 & Faktor Peralatan & 4,25 & 5 \\
\hline X6 & Faktor Kondisi Lapangan & 4,29 & 3 \\
\hline X7 & Faktor Diluar Kemampuan Kontraktor & 4,23 & 6 \\
\hline
\end{tabular}

Berdasarkan Tabel 3, maka nilai mean tertinggi diperoleh pada "Faktor Pelaksanaan dan Hubungan Kerja“, dengan nilai sebesar 4,31. Hal ini menunjukkan bahwa berdasarkan perpesi kontraktor faktor yang paling dominan penyebab keterlambatan proyek kontruksi dikabupaten Aceh Utara adalah "Faktor Pelaksanaan dan Hubungan Kerja ".

\subsection{Faktor penyebab keterlambatan proyek konstruksi}

Melalui analisis deskriptif setelah diidentifikasi nilai mean tertinggi hingga nilai mean terendah, maka urutan faktor-faktor penyebab terjadinya keterlambatan proyek konstruksi adalah disebabkan oleh faktor pelaksanaan dan hubungan kerja, faktor desain dan perencanaan, faktor kondisi lapangan, faktor tenaga kerja, faktor peralatan, faktor diluar kemampuan kontraktor, dan faktor material.

\subsection{Faktor dominan penyebab terjadinya keterlambatan proyek kontruksi}

Faktor-faktor penyebab terjadi keterlambatan proyek dengan nilai mean tertinggi diperoleh faktor pelaksanaan dan hubungan kerja dengan nilai sebesar 4,31. Hal ini menunjukan bahwa berdasarkan persepsi responden faktor dominan penyebab terjadinya keterlambatan proyek konstruksi di Kabupaten Aceh Utara adalah disebabkan oleh faktor pelaksanaan dan hubungan kerja. Faktor pelaksanaan dan hubungan kerja ini terdiri dari 12 indikator, diantaranya yaitu kordinasi proyek yang cukup rumit, pelaksanaan proyek berimprovisasi kerena kurang perencanaan, proses pekerjaan yang rumit dan khusus, padahal bisa 
disederhanakan, fungsi pengawasan lemah bahkan tanpa pengawasan, adanya banyak pekerjaan tambahan, perubahan jadwal pelaksanaan, kegagalan pemilik mengkoordinasi pekerjaan dari banyak kontraktor/sub kontraktor, daftar pekerjaan tidak lengkap, hanya diberikan secara sedikit demi sedikit, penundaan pekerjaan kerena alasan keuangan dan hukum, kesulitan pendanaan pekerjaan kerena alasan keuangan dan hukum, proses persetujuan ijin kerja yang bertele-tele, penyimpangan waktu pengiriman antara pengadaan material dengan peralatan.

\section{Kesimpulan dan Saran}

\subsection{Kesimpulan}

Terdapat 7 faktor terjadinya keterlambatan proyek diantaranya faktor desain dan perencanaan, faktor pelaksanaan dan hubungan kerja, faktor material, faktor tenaga kerja, faktor peralatan, faktor kondisi dan keadaan di lapangan, dan faktor di luar kemampuan kontraktor. Berdasarkan persepsi responden faktor yang paling dominan penyebab terjadinya keterlambatan proyek konstruksi di Kabupaten Aceh Utara disebabkan oleh faktor pelaksanaan dan hubungan kerja

\subsection{Saran}

Hasil penelitian ini akan digunakan sebagai alat bantu bagi kontraktor khususnya untuk wilayah Aceh Utara, untuk memperhatikan faktor-faktor yang berkaitan langsung dengan penyebab keterlambatan pelaksanaan proyek konstruksi yang berpengaruh terhadap biaya proyek. Diharapkan bagi peneliiti selanjutnya tidak terpaku pada faktor-faktor tersebut dalam meneliti penyebab keterlambatan pelaksanaan proyek kontruksi yang berpengaruh terhadap biaya proyek, akan tetapi mengkaji dan mengungkap faktor-faktor lain yang menyebabkan terjadinya keterlambatan pelaksanaan proyek kontruksi yang berpengaruh terhadap biaya proyek. Agar hasil penelitian dicapai dapat lebih maksimal mendekati bahkan sesuai dengan realita di lapangan.

\section{Daftar Kepustakaan}

Arikunto, S 2006, Prosedur Penelitian Suatu Pendekatan Praktik, Rineka Cipta, Jakarta.

Arikunto. 2010. Prosedur Penelitian: Suatu Pendekatan Praktek. Jakarta: Rineka Cipta.

Narbuko dan Achmadi 2004, Metodelogi Penelitian, Bumi Aksara, Jakarta.

Priyatno, D 2010, Teknik Mudah dan Cepat Melakukan Analisis Data Penelitian Dengan SPSS dan Tanya jawab Ujian Pendadaran, Gaya Media, Yogyakarta.

Triton, BP 2005, SPSS 13 Terapan Riset Statistik Parametrik, Andi, Yogyakarta. 